Commentary

\title{
Rethinking Planning Systems: A Plea for Self-Assessment and Comparative Learning
}

\author{
Frank J. D'hondt ${ }^{1}$, Kristof Van Assche ${ }^{2}$ and Barend Julius Wind ${ }^{3, *}$ \\ 1 ISOCARP-International Society of City and Regional Planners, 2517 AN The Hague, The Netherlands; \\ E-Mail: dhondt.f@gmail.com \\ 2 Faculty of Science, University of Alberta, T6G 2E9, Edmonton, Canada; E-Mail: vanassch@ualberta.ca \\ ${ }^{3}$ Department of Planning, Faculty of Spatial Sciences, University of Groningen, 9747 AD Groningen, The Netherlands; \\ E-Mail: b.j.wind@rug.nl \\ * Corresponding author
}

Submitted: 31 January 2020 | Accepted: 31 January 2020 | Published: 6 March 2020

\begin{abstract}
The authors reflect on recent experiences at UN-Habitat and other international organizations to rethink the roles of planning towards larger development goals and to reform planning systems in places most in need of them. They consider the difficulties but ultimate necessity to learn from a variety of contexts and experiences to articulate general orientations for planning and planning reform which can partly transcend context. Within the variety of planning experiences, and the experiences of lack of planning, one can discern principles which can be applied in many contexts, yet those include principles of contextualization and learning. Comparative learning underpins the attempts at finding general principles, and the local application of those principles further triggers processes of learning, including comparative learning. Local and grassroots planning capacity building is vital to locally apply and contextualize international planning guidelines.
\end{abstract}

\section{Keywords}

comparative learning; governance; international organizations; planning systems; reform

Issue

This commentary is part of the issue "Comparative Planning, Learning and Evolving Governance" edited by Kristof Van Assche (University of Alberta, Canada), Raoul Beunen (Open University of the Netherlands, The Netherlands) and Stefan Verweij (University of Groningen, The Netherlands).

(C) 2020 by the authors; licensee Cogitatio (Lisbon, Portugal). This article is licensed under a Creative Commons Attribution 4.0 International License (CC BY).

\section{Introduction}

The United Nations' New Urban Agenda (NUA) and UN-Habitat's International Guidelines on Urban and Territorial Planning (IG-UTP) urge planners worldwide to re-assess the policy tools and distributional outcomes of their own planning systems. Much academic interest is focused on system change towards more sustainable and equitable development in countries with already wellestablished planning systems. However, a majority of the Earth's surface is covered by countries with defective or outdated planning systems, often rooted in authoritarian, colonial or tribal rule (see ESPON, 2019; Ryser \& Franchini, 2015; UN-Habitat, 2009). In these countries, planning has the potential to improve the life of citizens. Even more than in the so-called developed world, new planning approaches are essential to combat poverty and to foster environmental sustainability in developing countries. However, exactly in these countries institutional change is difficult to achieve.

Where national governments-or local administrations-fail to establish accessible, just, transparent, adaptive, creative and pro-active planning systems, planners and civil society have the shared responsibility in establishing bottom-up planning practices that will contribute more compact, inclusive, climateresponsive, and better connected human settlements in harmony with terrestrial and non-terrestrial eco-systems. 
These practices could be considered as a first step towards a reform of the planning system to be aligned with the NUA (United Nations, 2016) and the IG-UTP (UN-Habitat, 2015)

\section{Redefining Planning Systems}

International-comparative research into planning systems, combined with the authors' experience as planning practitioners in both developed and developing countries, suggests that successful planning system reforms are based on a few principles. Planning needs to have a local and contextualized presence, has to be coherent, supported by evidence and public choice, by design skills and local knowledge, and by legislation enabling and delimiting planning powers. Different planning systems flourish in different governance environments, and reform of planning needs to take such environment into account.

Ironically, planning system reform is more difficult in countries with obsolete or inadequate planning legislations at the national and local level. Too often, planning systems are poorly integrated with planning and financial procedures, mechanisms and practices, resulting in unclear responsibilities. In turn, this produces inadequate plans and poor implementation of new plans and designs. For example, many adequate plans fail as the local administration has not yet secured land tenure and has no mechanisms to control buildability rights to manage urban development.

Because normative frameworks such as the Sustainable Development Goals (SDGs), the NUA as well the IG-UTP are by default of a global and universal nature, they do not explicitly address national and subnational planning systems as such. Planners thus need to develop these ideas into multi-level systems, rooted in the local territorial and governance context. National, subnational and local planning systems have to connect the dots sketched out by the NUA and IG-UTP. Different urban and territorial issues, different political, economic and legal systems, and different cultures and value systems all shape the planning system in different ways. Planning systems are always shaped by governance contexts imbuing them with path dependencies and limited autonomy.

The (re-)design of a planning system cannot be readily approached with a blueprint template. The approach we advocate uses the broad normative principles as a tool to assess, review, improve, adjust or reform a planning system within its context. Planning systems in different parts of the world may meet these principles in different ways, using different institutional structures and processes, and different methodologies and outcomes (UN-Habitat, 2009, pp. 18-19). The principles thus require contextualization, modification. Yet the use of general principles is worthwhile to coordinate internally and externally, and to allow for comparative learning. In the long run, they might shift, but for now, many problems are so obvious, that a level of generality is warranted.
We might not agree on the values which can then be enshrined in plans and enabling laws, yet we can agree right now, in the world as it is, that we need clearly defined property rights, linked unambiguously planning documents, and plans unambiguously relating to each other and to other institutions (including laws). At the same time, formalization of property rights can be abused to further marginalize poor families.

An international comparison suggests that a functional planning system contains at least three interdependent components: plans (including policies and designs), legislation and finance. Indeed, most would agree by now that planning cannot be reduced to the use of plans, and that their coordinative power has often been overestimated, yet spatial policies without plans miss out on coordinative opportunities, while stating common goals through spatial organization does not work without links with budgets and harder institutions, i.e., laws.

The international community has been active in strengthening planning systems in post-conflict and developing countries. Decades of internationalcomparative research show the importance of capacity building, of developing human resources, expertise and skills, so locals can define their own planning systems. Only when plans come about in co-creation between local and international experts, they can have a lasting impact on the planning system.

\section{Review to Adjust Planning Practices and Systems}

There are at least five compelling reasons why countries, cities and their citizens should jointly review the way urban and territorial planning and development is organised, managed and practiced implementing the NUA and attaining to the SDGs:

- The legal basis of national or devolved planning systems are often designed and developed in the 20th century and no longer fit for purpose in the fast urbanising 21st century;

- The planning system might be rooted in colonial times and not designed or developed according to the local context and specific challenges and opportunities of communities and territories;

- The planning system might be designed and developed under a different socio-ideological framework that no longer exist;

- The planning system is only addressing the formal planning while much if not most of the recent and ongoing urbanisation occurs outside the formal planning system;

- The planning system in place might simply not be up to task to deliver on the SDGs (goal 10, inequality, and 11 , sustainable communities, in particular) and the NUA.

The history of Western involvement in planning in developing countries, ranging from (neo-)colonial approaches 
to modernist interventions, taught us that planning reform and broader institutional reform (e.g., towards 'development') almost never works if it is a matter of coercion, by political or economic elites, by foreign powers, by experts (Van Assche \& Hornidge, 2015). Some form of local sensitivity is essential, ranging from participation of local actors, awareness of the culture, history and landscape, to an understanding of the interplay between formal and informal institutions (Van Assche, Beunen, \& Duineveld, 2014). Participation and representation generally require multi-level, layered institutions. In the context of authoritarian or failing states full public participation can only be achieved by the 'democratisation' of all components and phases of the planning system and processes. At the other hand, participation of local stakeholders in one or several stages of the planning cycle could be the seed for further democratization.

Planning reform has to be a planned enterprise itself, rather than ad hoc responses to disasters or critiques. It will likely be an adjustment of the existing situation rather than a tabula rasa exercise. Therefore, planning reform has to be inspired by a comprehensive review of the planning system and its distributional outcomes in its governance context. We advocate for the use of participatory forms of assessment by relevant stakeholders. Relevant stakeholders might differ from country to country, but range from governmental actors from different scale levels, (international) experts and civil society actors representing citizens with a different ethnic or socioeconomic position. It is of utmost importance to include representatives of vulnerable groups as a form of advocacy planning. Too often their 'right to the land' or 'right to the city' is violated when market-driven reforms are executed. A dialogue between relevant stakeholders allows countries with limited planning systems to leapfrog towards better designed systems by earning from the hard lessons learnt by older planning systems.

In line with the international studies quoted, we argue that such review has to include at least three components:

- Planning review: assessment of policies, plans and designs to enable desired urban and territorial developments;

- Legal review: assessment of rules and regulations related to land, tenure, housing and spatial planning;

- Financial review: assessment of the mechanisms in place to finance the desired developments.

Local actors that are capable of carrying out a planning system review, or contributing to planning reforms are in many countries not readily available. An educational review could analyse whether the educational system produces the experts needed, or which skills should be added to university curricula (such as an understanding of multi-level governance and multi-scale planning).
Depending on the situation, communities or countries can choose for a rapid assessment or a more comprehensive one. The studies referred to include sets of principles and recommendations which can be fully embraced by self-assessing communities, or modified, selectively used, depending on local values and priorities.

\section{How to Turn Review into Reform?}

Having designed a self-assessment process and methods consistent with a clearly defined purpose, established buy-in across the stakeholder-organisations, and secured the participation of a wide variety of ethical, credible evaluators, the exercise then needs to be pursued with rigour. Stakes can be high in changing deep-rooted planning rules and the information on which the changes are based needs to be reliable and complete.

Gradually building up knowledge across the stakeholder organisations about the assessment's findings, means that the findings can be verified and gradually understood and accepted. In the final reporting, the assessment team can then move more quickly into action because the stage has been set for the team to move stakeholders to respond to the findings by committing to action. Even the best designed assessment does not necessarily lead to implementation, of course, and continuous observation and adaptation by the assessment team is recommended. The team has to respond continuously to its own findings, regarding issues, but also regarding possible solutions, reform options which might address the issue and are also feasible to achieve taking the existing governance configuration as a starting point (Van Assche, Beunen, \& Duineveld, 2013). Regarding the goals of reform and of the reformed planning system: These have to be set collectively, as part of the self-assessment, but as a rule of thumb one can say that they should be primarily designed to enable sustainable and equitable development.

\section{Conclusion}

Reviewing and reforming planning systems is obviously a complex and lengthy process. Many countries do not even have a national system in place to reform. Our contemporary social and environmental challenges are too large to wait for planners to come up with 'perfect system reforms.' The perfect is the enemy of the good. That is why we should encourage cities and their local authorities to act in the absence of perfect national planning systems, with the legal, financial and planning means at their disposal. That is also why we need to encourage communities and their trained and barefoot planners to act in the absence of a just local planning systems (D'hondt, 2019).

Planning has to be understood as embedded in governance, and planning reform has to take into account the state and evolutions of governance systems. Not 
every planning ideal makes sense for every community and not every ideal is feasible from each starting point. The rich experience with planning reform, with institutional reform and with development projects represented in international organizations such as UN-Habitat and ISOCARP, allow us to draw some general conclusions, beyond the need for context-sensitivity. Internationalcomparative research, case study reports and local policies show that (1) planning is able to improve the quality of life in developing countries while contributing to the SDGs, and (2) that planning system reform is urgently needed as they tend to be rooted in the past, and build on old analyses of old problems. General reform recommendations, e.g., under the heading of good governance, or just labelled as institutional reform, rule of law, or market reform are not enough; spatial planning cannot be forgotten as a major road to development, which, under current conditions, has to be understood as sustainable and equitable development (Van Assche \& Hornidge, 2015).

The lessons regarding planning reform drawn from and within international organizations do not stem from one formal research project, nor from a shared methodology of comparative research. Even so, it is a matter of common sense to see that these lessons, the principles for planning systems and planning reform discerned there, came out of knowledge of many planning systems and many attempts at reform. They also came out of experience in countries where a notable absence of planning systems or coherent spatial governance created some notably similar results.

The principles for reform which can transcend context are general though and include mechanisms to render planning reform context sensitive. This again entails learning, first of all self-assessment but also comparative learning, as lessons from other places can come in through diverse actors involved in participatory assessment. Our message to local and barefoot-planners is to keep on going, using stakeholder dialogue as a lever of change, whereas our message to international planners is to forget about all the reasons not to engage with countries with failing planning systems, as this is highly needed to contribute to the SDGs and the quality of life for millions.

\section{Conflict of Interests}

The authors declare no conflict of interests.

\section{References}

D'hondt, F. (2019). Beyond the plan: The need to build in-house capacity to plan, design and implement urban and territorial strategic spatial plans. ISOCARP Review, 2019(15), 158-185.

ESPON. (2019). Comparative analysis of territorial governance and spatial planning systems in Europe. Luxembourg: COMPASS.

Ryser, J., \& Franchini, T. (Eds.). (2015). International manual of planning practice. The Hague: ISOCARP.

UN-Habitat. (2009). Planning sustainable cities: Global report on human settlements 2009. London: UN-Habitat.

UN-Habitat. (2015). International guidelines on urban and territorial planning. London: UN-Habitat.

United Nations. (2016). New urban agenda. New York, NY: United Nations.

Van Assche, K., Beunen, R., \& Duineveld, M. (2013). Evolutionary governance theory: An introduction. Heidelberg: Springer.

Van Assche, K., Beunen, R., \& Duineveld, M. (2014). For$\mathrm{mal} /$ informal dialectics and the self-transformation of spatial planning systems: An exploration. Administration \& Society, 46(6), 654-683.

Van Assche, K., \& Hornidge, A. K. (2015). Rural development: Knowledge and expertise in governance. Wageningen: Wageningen Academic Publishers.

\section{About the Authors}

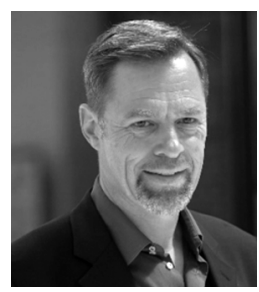

Frank J. D'Hondt is Secretary General of the International Society of City and Regional Planners (ISOCARP) and Founder/Managing Director of the Territorial Capital Institute. Frank is a free-lance senior territorial planning advisor, based in Athens, Greece, and currently working with mainly United Nations agencies in different cities and territories around the world. Frank authored two UN-Habitat publications, one of them "Visioning as Participatory Planning Method," and lately also the handbook to apply the IG-UTP. He regularly publishes articles in planning magazines, speaks at international planning conferences and holds lectures at several universities.

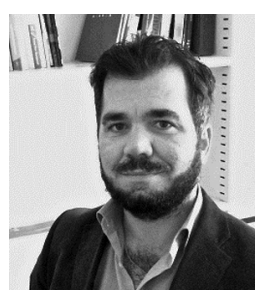

Kristof Van Assche is interested in evolution and innovation in governance, with focus areas in spatial planning and design, development and environmental policy. He worked in various countries, and often combines fieldwork with theoretical reflection, mainly on system theories, interpretive policy analysis, institutional economics and post-structuralism. He held visiting positions at McGill University, Krakov Agricultural University, Wageningen University and Bonn University. Geographically, his work spans Europe, the Americas, Central Asia and the Caucasus. He published widely on these topics. 


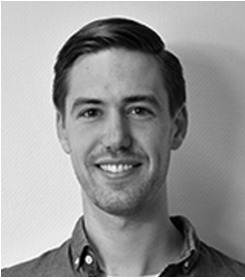

Barend Julius Wind is Assistant Professor socio-spatial planning at the University if Groningen, in the Netherlands. He is interested in the social and spatial consequences of major socio-economic changes that have occurred since the 1980s (globalization, financialization, welfare state retrenchment). In his work, he applies social justice theory to contribute to institutional design in Europe and (post-) conflict areas. Housing inequalities are the main focus of his research. 